\section{OPEN ACCESS}

Edited by:

Luciane Cruz Lopes,

Universidade de Sorocaba, Brazil

Reviewed by:

Ludo Haazen,

Self-employed, Belgium

André Oliveira Baldoni,

Universidade Federal de São João del-Rei, Brazil

*Correspondence:

Ismar Lima Cavalcant ismarcavalcanti@gmail.com

Specialty section

This article was submitted to Pharmaceutical Medicine and Outcomes Research,

a section of the journal Frontiers in Pharmacology

Received: 18 January 2019 Accepted: 04 April 2019 Published: 26 April 2019

Citation:

Cavalcanti IL, Lima FLT, Silva MJS, Cruz Filho RA, Braga ELC and Verçosa N (2019) Use Profile of Magnesium Sulfate in Anesthesia in Brazil. Front. Pharmacol. 10:429, doi: 10.3389/fphar.2019.00429

\title{
Use Profile of Magnesium Sulfate in Anesthesia in Brazil
}

\begin{abstract}
Ismar Lima Cavalcanti ${ }^{1,2 *}$, Fernando Lopes Tavares de Lima ${ }^{2}$, Mario Jorge Sobreira da Silva ${ }^{2}$, Rubens Antunes da Cruz Filho ${ }^{3}$, Estêvão Luiz Carvalho Braga ${ }^{1}$ and Nubia Verçosa ${ }^{4}$
\end{abstract}

${ }^{1}$ Department of General and Specialized Surgery, Anesthesiology, Fluminense Federal University, Niterói, Brazil, ${ }^{2}$ Coordination for Education, Brazilian National Cancer Institute (INCA), Rio de Janeiro, Brazil, ${ }^{3}$ Department of Clinical Medicine, Fluminense Federal University, Niterói, Brazil, ${ }^{4}$ Department of Surgery, Anesthesiology, Federal University of Rio de Janeiro, Rio de Janeiro, Brazil

Objectives: The use of magnesium sulfate in the perioperative period has several benefits, including analgesia, inhibition of the release of catecholamines and prevention of vasospasm. The aim of this survey was to provide an overview of the use of magnesium sulfate in anesthesia.

Method: This was a prospective descriptive cross-sectional study. An online questionnaire was sent to 9,869 Brazilian anesthesiologists and trainees. The questionnaire comprised closed questions mainly regarding the frequency, clinical effects, adverse events, and doses of magnesium sulfate used in anesthesia.

Results: Of the 954 doctors who responded to the survey, 337 (35.32\%) reported using magnesium sulfate in anesthesia. The most commonly cited clinical effects for the use of magnesium sulfate in anesthesia were $(n / \%)$ : postoperative analgesia $(245 / 72.70 \%)$, reduction of anesthetic consumption (240/71.21\%) and prevention and treatment of preeclampsia and seizures in eclampsia (220/65.28\%). The most frequently reported adverse events were hypotension (187/55.48\%), residual neuromuscular blockade (133/39.46\%), hypermagnesemia (30/8.90\%), and intravenous injection pain (26/7.71\%). The intravenous doses of magnesium sulfate used in most general anesthesia inductions were between 30 and $40 \mathrm{mg} \cdot \mathrm{kg}^{-1}$.

Conclusions: Magnesium sulfate is an important adjuvant drug in the practice of anesthesia, with several clinical effects and a low incidence of adverse events when used at recommended doses.

Keywords: anesthetics (MeSH), analgesics, magnesium sulfate, survey, adverse events

\section{INTRODUCTION}

Magnesium is the fourth most common ion in the body, and it participates in several cellular processes, including protein synthesis, neuromuscular function and stability of nucleic acid, as well as regulating other electrolytes such as calcium and sodium. Magnesium acts as a cofactor in protein synthesis, neuromuscular function and stability and the function of nucleic acids. It is a component of adenosine 5-triphosphatases and an endogenous regulator of other electrolytes. It is a calcium antagonist because it is a non-competitive inhibitor of calcium channels with inositol triphosphate. Magnesium modulates sodium and potassium currents and, as a consequence, interferes with the transmembrane potential. It is a central nervous system depressant, antagonizing N-methyl-Daspartate (NMDA) and inhibiting the release of catecholamines (Herroeder et al., 2011). 
Some studies have shown that the use of magnesium sulfate as an adjunct in anesthesia reduces intraoperative consumption of anesthetics (Koinig et al., 1998; Seyhan et al., 2006; Ryu et al., 2008; Forget and Cata, 2017). It also provides better analgesia and reduces the amount of morphine used in the postoperative period (Mentes et al., 2008; Dabbagh et al., 2009; Hwang et al., 2010). Studies in clinical practice have demonstrated the inhibitory effects of magnesium on the release of catecholamines (Herroeder et al., 2011) through better hemodynamic control during laryngoscopy (Puri et al., 1998; Shin et al., 2011) and pneumoperitoneum insufflation for videolaparoscopy (Mentes et al., 2008). Magnesium sulfate also reduces levels of noradrenaline and vasopressin during anesthesia (Jee et al., 2009).

Other benefits of using intraoperative magnesium have been reported, including hemodynamic control in surgeries for resection of pheochromocytoma (James and Cronjé, 2004), reduced incidence of atrial fibrillation in myocardial revascularization surgeries (Toraman et al., 2001), and prevention of vasospasm (Wong et al., 2006) and neurological protection after subarachnoid hemorrhage (Schmid-Elsaesser et al., 2006). The attenuation of the release of catecholamines by the adrenal glands and antagonism to calcium in smooth muscle cells of arterioles are possible mechanisms of action (Herroeder et al., 2011).

The clinical duration of nondepolarizing neuromuscular blockers is prolonged with the use of magnesium sulfate in anesthesia (Fuchs-Buder et al., 1995; Kussman et al., 1997; Czarnetzki et al., 2010; Rotava et al., 2013). Magnesium interferes with neuromuscular function by reducing the conductance of calcium in presynaptic membranes, decreasing the amount of acetylcholine released by motor neurons (Herroeder et al., 2011). It may also reduce post-synaptic sensitivity to acetylcholine or have a direct effect on the membrane potential of muscle cells (Del Castillo and Engbaek, 1954).

This survey was conducted to contribute evidence on the use of magnesium sulfate as adjunct of anesthesia due to its potential clinical benefits.

The primary objective of this study was to know the use profile of Magnesium Sulfate in Anesthesia in Brazil.

\section{MATERIALS AND METHODS}

The descriptive study was approved by the Research Ethics Committee of the Fluminense Federal University, Niterói, RJ, Brazil (CAAE 35038614.0.0000.5243, opinion 884.839 , dated $11 / 13 / 2014)$. The informed consent form was signed electronically.

All the anesthesiologists and trainees members of Brazilian Society of Anesthesiology in 2015 were invited to participate. A self-administered electronic questionnaire was sent via e-mail to 9,869 potential participants of the research using the Survey Monkey software. The invitation was sent by 3 times with the 10-day interval between them.

We did not find in the literature a data collection instrument on the subject of this research. The lead researcher created the electronic questionnaire used in this research, composed of 10 closed questions that addressed the following aspects: duration of practice of anesthesiology, use of magnesium sulfate and other anesthesia adjuvants, indications, complications and doses of magnesium sulfate in anesthesia (Figure 1).

The instrument was pre-tested in two stages. In the first stage, the relevance of the instrument was evaluated and was carried out by the researchers themselves. In the second stage, the questionnaire was evaluated by 8 anesthesiologists and the results were used to create the final version of the questionnaire used in the research.

Data were analyzed using descriptive statistics. The original data can be accessed in the Supplementary Table 1.

\section{RESULTS}

Survey responses were received from 945 (9.57\%) participants. The length of time of anesthesia practice among the respondents is shown in Table 1.

Of the 945 anesthesiologists who responded to this survey, $331(35.02 \%)$ reported using magnesium sulfate in anesthesia. The frequency of use of adjuvant drugs in anesthesia is described in Table 2.

The number and percentage of clinical effects $(n / \%)$ for the use of magnesium sulfate in anesthesia were (in descending order, more than one response per participant allowed): postoperative analgesia (242/73,11\%), reduction of anesthetic consumption (237/71.60\%), prevention and treatment of preeclampsia and seizures in eclampsia (218/65.86\%), prevention and treatment of arrhythmias (175/52.87\%), reduction of the dose of neuromuscular blockers (168/50.75\%), prevention of postoperative chronic pain (167/50.45\%), bronchodilation $(165 / 49.84 \%)$, prevention of hyperalgesia post remifentanil use $(160 / 48.34 \%)$, hypomagnesemia prevention in large surgeries $(128 / 38.67 \%)$, induced systemic arterial hypotension (112/33.83\%), brain protection (95/28.70\%), sedation $(86 / 25.98 \%)$, reduction of surgical bleeding or reduction of perioperative blood replacement (74/22.35\%), management of pheochromocytoma (72/21.75\%), prevention and treatment of agitation in emergence from general anesthesia (64/19.33\%), inhibition of preterm birth (59/17.82\%), prevention of myocardial ischemia (54/16.31\%), prevention and treatment of shivering (50/15.10\%), facilitation of tracheal intubation without the use of neuromuscular blocker agent (44/13.29\%), reduction of nausea and vomiting $(39 / 11.78 \%)$, prevention and treatment of laryngospasm (38/11.48\%), control of fasciculation and myalgia after succinylcholine (31/9.36\%), prevention of myoclonus after intravenous injection of etomidate (24/7.25\%), treatment of tetanus (20/6.04\%), adjuvant in spinal anesthesia $(19 / 5.74 \%)$, decrease in platelet aggregation (14/4.23\%), attenuation of the sympathetic response to tracheal intubation $(1 / 0.30 \%)$ and extension of duration of motor block on subdural anesthesia $(1 / 0,30 \%)$.

All anesthesiologists reported using the intravenous route $(331 / 100.00 \%)$ to administer magnesium sulfate. Other routes were used less frequently: muscular (16/4.83\%), nerve plexus 


\section{Questionnaire - Use of Magnesium Sulphate in Anesthesia in Brazil}

1. Duration as anesthesiologist:
( ) 1 to 5 years
( ) 6 to 10 years
( ) 11 to 15 years
( ) 6 to 20 years
( ) more than 20 years

2. Do you use magnesium sulfate in anesthesia?

( ) yes ( ) not

3. Except for magnesium sulfate, which of the adjuvants do you use in anesthesia? (More than one answer is possible)

( ) clonidine ( ) dexmedetomidine ( ) ketamine ( ) lidocaine ( ) other ( ) I do not use anesthesia adjuvants

If you use magnesium sulfate, please answer the following questions:

4. What is the clinical effect (s) for the use of magnesium sulphate during anesthesia? (More than one answer is possible)

( ) prevention of myocardial ischemia

( ) brain protection

( ) reduction of the dose of neuromuscular blocker

( ) attenuation of sympathetic response to tracheal intubation

( ) postoperative analgesia

( ) decreased anesthetic consumption

( ) inhibition of preterm birth

( ) prevention and treatment of preeclampsia and seizures in eclampsia;

( ) bronchodilation

( ) adjuvant in spinal anesthesia

( ) prevention / treatment of cardiac arrhythmias

( ) handling of pheochromocytoma

( ) prevention of hypomagnesemia in large surgeries

( ) decreased platelet aggregation

( ) prevention / treatment of laryngospasm

( ) prevention of myoclonus after venous injection of etomidate

( ) prevention of chronic postoperative pain

( ) facilitation of tracheal intubation without the use of neuromuscular blocker

( ) control of fasciculation and myalgia after succinylcholine

( ) prevention of hyperalgesia after use of remifentanil

( ) prevention / treatment of shivering

( ) reduction of surgical bleeding

( ) reduction of perioperative blood replacement

( ) tetanus treatment

( ) reduction of nausea and vomiting

( ) induced hypotension

( ) sedation

( ) prevention / agitation treatment on awakening from anesthesia

( ) prevention / treatment of chronic pain

( ) other

5. Which route (s) do you use to administer magnesium sulfate? (More than one answer is possible)

$\begin{array}{llllll}\text { ( ) intravenous ( ) intramuscle ( ) spinal ( ) nerve plexus ( ) intravenous regional ( ) surgical wound infiltration } & \end{array}$

6. Which of the adverse events of using magnesium sulfate in anesthesia have you witnessed? (More than one answer is possible)

( ) residual neuromuscular blockade ( ) intravenous injection pain ( ) respiratory depression ( ) systemic arterial hypotension

( ) hypermagnesemia ( ) other

7. In the case of observed adverse events, how do you classify them in terms of severity? (More than one answer is possible)

( ) mild ( ) moderate ( ) severe ( ) death

8. What is the intravenous dose you often use in inducing general anesthesia? (only one answer)

$\begin{array}{llllll}\text { ( ) }<30 \mathrm{mg} \cdot \mathrm{kg}^{-1} & \text { ( ) } 30 \text { to } 40 \mathrm{mg} \cdot \mathrm{kg}^{-1} & \text { ( ) } 40 \text { to } 50 \mathrm{mg} \cdot \mathrm{kg}^{-1} & \text { ( ) } 50 \text { to } 60 \mathrm{mg} \cdot \mathrm{kg}^{-1} & \text { ( ) }>60 \mathrm{mg}^{-\mathrm{kg}^{-1}} \quad \text { ( ) I do not use inducing doses }\end{array}$

9. What venous dose do you often use to maintain general anesthesia? (only one answer)

$\begin{array}{llllll}\text { ( ) }<30 \mathrm{mg} \cdot \mathrm{kg}^{-1} & \text { ( ) } 30 \text { to } 40 \mathrm{mg} \cdot \mathrm{kg}^{-1} & \text { ( ) } 40 \text { to } 50 \mathrm{mg} \cdot \mathrm{kg}^{-1} & \text { ( ) } 50 \text { to } 60 \mathrm{mg} \cdot \mathrm{kg}^{-1} & \text { ( ) }>60 \mathrm{mg} \cdot \mathrm{kg}^{-1} & \text { ( ) I do not use maintenance doses }\end{array}$

10. Doses used for sedation?

$\begin{array}{lllll}\text { ( ) }<30 \mathrm{mg} \cdot \mathrm{kg}^{-1} & \text { ( ) } 30 \text { to } 40 \mathrm{mg} \cdot \mathrm{kg}^{-1} & \text { ( ) } 40 \text { to } 50 \mathrm{mg} \cdot \mathrm{kg}^{-1} & \text { ( ) } 50 \text { to } 60 \mathrm{mg} \cdot \mathrm{kg}^{-1} \quad \text { ( ) }>60 \mathrm{mg} \cdot \mathrm{kg}^{-1}\end{array}$

( ) I do not use magnesium sulfate for sedation

FIGURE 1 | Electronic questionnaire used in research "Use of Magnesium Sulfate in Anesthesia in Brazil." Brazil, 2015. 
TABLE 1 | Distribution of anesthesiologists that answered the questionnaire ( $n=945)$ by the duration of anesthesia practice $(n, \%)$.

\begin{tabular}{lcc}
\hline Time of practice of anesthesia & $\boldsymbol{n}$ & $\%$ \\
\hline Trainee & 135 & 14.29 \\
$1-5$ years & 240 & 25.40 \\
$6-10$ years & 116 & 12.27 \\
$11-15$ years & 83 & 8.78 \\
$16-20$ years & 82 & 8.67 \\
21 years or more & 289 & 30.59
\end{tabular}

Brazil, 2015.

TABLE 2 | Frequency of use of adjuvant drugs in anesthesia (n, \%).

\begin{tabular}{lcc}
\hline Adjuvant drug & $\boldsymbol{n}$ & $\%$ \\
\hline Clonidine & 805 & 85.19 \\
Ketamine & 689 & 72.91 \\
Lidocaine & 614 & 64.97 \\
Dexmedetomidine & 417 & 44.12 \\
Magnesium sulfate & 331 & 35.02 \\
No use of adjuvant & 39 & 4.13 \\
\hline
\end{tabular}

More than one response per participant was possible $(n=945)$. Brazil, 2015.

TABLE 3 | Frequency of adverse events during use of magnesium sulfate witnessed at least once by the anesthesiologist.

\begin{tabular}{lcc}
\hline Adverse events & $\boldsymbol{n}$ & $\%$ \\
\hline Systemic arterial hypotension & 184 & 55.59 \\
Residual neuromuscular blockade & 131 & 39.57 \\
Hypermagnesemia & 28 & 8.45 \\
Intravenous injection pain & 22 & 6.64 \\
Respiratory depression & 22 & 6.64 \\
Heat sensation & 4 & 1.20 \\
Bradycardia & 4 & 1.20 \\
Facial/cervical flushing & 2 & 0.60 \\
Tachycardia & 2 & 0.60 \\
Intense sedation & 2 & 0.60 \\
Cardiac arrhythmia & 1 & 0.30 \\
Prolonged emergence from & 1 & 0.30 \\
anesthesia & & \\
Myocardial depression & 1 & 0.3 \\
None & 40 & 12.08 \\
\hline
\end{tabular}

More than one response per participant was possible $(n=331)$. Brazil, 2015.

$(6 / 1.81 \%)$, spinal $(3 / 0.90 \%)$, regional intravenous anesthesia $(3 / 0.90 \%)$, wound infiltration $(2 / 0.60 \%)$, inhalation $(2 / 0.60 \%)$, and oral $(1 / 0.30 \%)$.

Table 3 shows the frequency of adverse events during use of magnesium sulfate witnessed at least once by the anesthesiologist. The most commonly reported were hypotension, residual neuromuscular blockade, hypermagnesemia, intravenous injection pain, and respiratory depression.

Of the adverse events reported, $73.78 \%$ of the cases were considered of mild gravity (see Table 4). It should be noted that
TABLE 4 | Rate of intensity level of adverse events witnessed by anesthesiologists using magnesium sulfate anesthesia $(n=305)$.

\begin{tabular}{lcc}
\hline & N & $\%$ \\
\hline Mild & 225 & 73.78 \\
Moderate & 71 & 23.27 \\
Severe & 9 & 2.95 \\
\hline
\end{tabular}

Brazil, 2015.

TABLE 5 | Magnesium sulfate intravenous doses most commonly used in the induction of general anesthesia and sedation $(n=331)$.

\begin{tabular}{llcc}
\hline & Doses & $\boldsymbol{n}$ & $\%$ \\
\hline $\begin{array}{llc}\text { Induction of general } \\
\text { anesthesia }\end{array}$ & $<30 \mathrm{mg} \cdot \mathrm{kg}^{-1}$ & 55 & 16.61 \\
& $30-40 \mathrm{mg} \cdot \mathrm{kg}^{-1}$ & 114 & 34.45 \\
& $40-50 \mathrm{mg} \cdot \mathrm{kg}^{-1}$ & 47 & 14.20 \\
& $50-60 \mathrm{mg} \cdot \mathrm{kg}^{-1}$ & 9 & 2.71 \\
& No use for induction of & 106 & 32.03 \\
& general anesthesia & & \\
& $<30 \mathrm{mg} \cdot \mathrm{kg}^{-1}$ & 58 & 17.52 \\
Sedation & $30-40 \mathrm{mg} \cdot \mathrm{kg}^{-1}$ & 28 & 8.46 \\
& $40-50 \mathrm{mg} \cdot \mathrm{kg}^{-1}$ & 10 & 3.02 \\
& $50-60 \mathrm{mg} \cdot \mathrm{kg}^{-1}$ & 1 & 0.30 \\
& No use for sedation & 234 & 70.70 \\
\hline
\end{tabular}

Brazil, 2015.

some adverse events were reported as severe, i.e., respiratory depression (4), hypotension (4), residual curarisation (4), hypermagnesemia (2) and bradycardia (1).

Table 5 shows the dosages of intravenous magnesium sulfate commonly used for induction of general anesthesia and sedation.

\section{DISCUSSION}

Little or no scientific literature exists that reports on surveys on the use of magnesium sulfate in anesthesia.

Approximately $10 \%$ of those who received the invitation to participate completed the survey, specifically, 945 anesthesiologists. Several medical polls have reported similar response rates (Naguib et al., 2010; Locks et al., 2015). Low adherence of participants can be explained by the electronic method used for data collection.

\section{Duration of Anesthesia Practice of the Survey Participants}

In the present survey, anesthesiologists with more than 20 years of anesthesia practice $(30.59 \%)$ reported using magnesium sulfate in anesthesia and sedation most frequently; this group was followed by those with between 1 and 5 years of clinical practice (25.40\%). The frequent use of magnesium sulfate among the more experienced anesthesiologists may stem from common use in certain specialties, particularly obstetrics. The high frequency of use of magnesium sulfate among the younger group of anesthesiologists may be result of the recent attention being paid 
to this drug, as well as the introduction of multimodal analgesic and anesthesia techniques (Czarnetzki et al., 2010; Herroeder et al., 2011; Shin et al., 2011; Rotava et al., 2013).

\section{Adjuvant Drugs in Anesthesia}

Anesthesia adjuvants are agents that are administered in association with anesthetics to increase effectiveness, improve delivery, or decrease required dosage. The survey showed that the drug most commonly used in Brazil as an anesthesia adjuvant is clonidine (85.18\%); magnesium sulfate (35.02\%) ranks fifth among the medicines included as possible survey responses.

Giovannitti et al. (2015) postulated that agonists of the $\alpha-2$ adrenergic receptors, including clonidine and dexmedetomidine, are important tools in the arsenal of modern anesthesia because of their ability to induce calm without causing respiratory depression. They also promote cardiovascular stability and reduce anesthetic requirements.

The drug reported as the second most frequently used adjuvant was ketamine. Bakan et al. (2014) conducted a randomized clinical trial and showed that ketamine, when associated with remifentanil in total intravenous anesthesia in children, is well suited to rigid bronchoscopic procedures.

Although this survey found that lidocaine ranked third on the list of most used drugs, Kranke et al. (2015), in a systematic review, reported that there is only little or moderate evidence that a continuous infusion of lidocaine has an impact on pain intensity, especially in the early postoperative period, or on postoperative nausea. There is limited evidence that it has consequences in other clinical outcomes, such as gastrointestinal recovery, length of hospital stay and opioid use (Kranke et al., 2015).

Gupta et al. (2006) demonstrated that magnesium sulfate has anesthetic, analgesic and muscle relaxing effects and significantly reduces the need for anesthetic drugs and neuromuscular blockers.

\section{Clinical Effects of Magnesium Sulfate in Anesthesia}

As noted in this survey, there is a wide range of clinical effects for the use of magnesium sulfate in anesthesia. The great variety of clinical effects could be explained by the substantial involvement of magnesium in the physiology of various organs and systems.

Magnesium participates in over 325 cellular enzyme systems and is the second most abundant intracellular cation after potassium. Magnesium participates in numerous physiological and homeostatic functions, such as binding of hormone receptors, the transmembrane flow of ions, regulation of adenylate cyclase, calcium release, muscle contraction, cardiac excitability, neuronal activity, control of vasomotor tone and release of neurotransmitters, blood pressure and peripheral blood flow. $\mathrm{Mg}^{2+}$ modulates and controls the input of cell $\mathrm{Ca}^{2+}$ and $\mathrm{Ca}^{2+}$ release from the sarcoplasmic reticulum (Altura, 1994).

Magnesium is essential in the transfer, storage and utilization of energy in cells. The intracellular level of free $\mathrm{Mg}^{2+}\left(\left[\mathrm{Mg}^{2+}\right] \mathrm{i}\right)$ regulates intermediate metabolism, synthesis and structure of DNA and RNA, cell growth, reproduction and membrane structure (Altura and Altura, 1996).
Dubé and Granry (2003) cited the therapeutic use of magnesium in the following anesthesia, intensive care and emergency situations: prevention and treatment of hypomagnesemia, induction of anesthesia, control of pheochromocytoma, cardiac arrhythmias, preeclampsia and eclampsia, perioperative analgesia, asthma, myocardial infarction, hypertensive crisis, and insulin resistance.

Roscoe and Ahmed conducted a postal survey of cardiac anesthetists in the United Kingdom, to determine the extent of magnesium sulfate $\left(\mathrm{MgSO}_{4}\right)$ use and the main indications for its administration. The most common indications for administration were arrhythmia prophylaxis and treatment, myocardial protection and treatment of hypomagnesemia (Roscoe and Ahmed, 2003).

All the clinical effects for the use of magnesium sulfate in anesthesia presented by the anesthesiologists participating in this survey have been reported in other publications, including various systematic reviews and meta-analyses, although some of them are still subjects of controversy Beşogul et al., 2009; Gozdemir et al., 2010; Rhee et al., 2012; Abdulatif et al., 2013; Rotava et al., 2013; Agrawal et al., 2014; Ahsan et al., 2014; Crowther et al., 2014; Kahraman and Eroglu, 2014; Kew et al., 2014; Marzban et al., 2014; Rodrigo et al., 2014; Srebro et al., 2014; Uludag et al., 2014; Berhan and Berhan, 2015; Kim et al., 2015; Safavi et al., 2015; Vigil-De Gracia and Ludmir, 2015; Demiroglu et al., 2016; Green, 2016; Griffiths and Kew, 2016; Jangra et al., 2016; Juibari et al., 2016; Maged et al., 2016; Naghipour et al., 2016; Rodríguez-Rubio et al., 2016, 2017; Soltani et al., 2016; Thomas and Behr, 2016; Ulm et al., 2016; Vendrell et al., 2016; Xie et al., 2016, 2017; Brookfield et al., 2017; Haryalchi et al., 2017; Kutlesic et al., 2017; Lecuyer et al., 2017; McKeown et al., 2017; Mendonca et al., 2017; Salaminia et al., 2018; Zhang et al., 2018.

\section{Adverse Events of Magnesium Sulfate Use and Classification of Intensity}

Herroeder et al. (2011) reported that the vasodilator effect of magnesium is the likely cause of burning or heat sensations in the body. Prolonged PR and QT intervals as well as atrioventricular blockage may occur. Toxicity occurs with the administration of venous doses greater than $30 \mathrm{~g}$ or with plasma concentrations above $14.4 \mathrm{mg} / \mathrm{dl}$ (Herroeder et al., 2011). Hypermagnesemia is manifested by abolition of tendon reflex; treatment consists of calcium gluconate, furosemide furosemide and hemodialysis (Herroeder et al., 2011).

In this survey, $2.95 \%$ of respondents reported severe complications from the use of magnesium sulfate. It is worth mentioning that the occurrence of severe adverse events is of fundamental importance, demonstrating that the administration of magnesium sulfate is not risk free. As in the present research, Herroeder et al. (2011) related as severe adverse events from the use of magnesium sulfate: arterial hypotension, bradycardia, muscle weakness, and respiratory depression. The results of our survey demonstrated similar results. Despite the occurrence of reports of serious AEs, the use of magnesium sulfate can be safe in recommended doses with close monitoring of patients (Kutlesic et al., 2017). 
Marret and Ancel (2016) used magnesium sulfate in obstetric patients at an initial venous dose of $4 \mathrm{~g}$ followed by $1 \mathrm{~g} / \mathrm{h}$, without exceeding the cumulative total dose of $50 \mathrm{~g}$. In their analysis of short and medium-term outcomes, they found no serious maternal adverse effects nor adverse effects on the newborns.

Griffiths and Kew (2016) observed few adverse effects when intravenous magnesium sulfate was used for treatment of asthma in children in the emergency department.

Wilson et al. (2014) realized a retrospective cohort study to evaluated the tolerability and safety of high doses of intravenous magnesium sulfate for tocolysis in preterm labor. The frequency of severe adverse events was $5.3 \%$ while in our survey it was $2.95 \%$. This difference can be explained because all patients in the study received high doses of magnesium sulfate. They concluded that side effects occurred in 9 out of 10 patients and were considered severe for 1 out of every 20 pregnant women.

\section{Intravenous Dose of Magnesium Sulfate Most Frequently Used in Induction of General Anesthesia and Sedation}

Germano Filho et al. (2015), in a randomized controlled study, demonstrated a significant increase in magnesium plasma concentrations after infusions of $40 \mathrm{mg} \cdot \mathrm{kg}^{-1}$ solution containing magnesium sulfate among ASA 1 or 2 patients. This confirmed that this dose is capable of increasing magnesium serum levels.

The magnesium sulfate doses reported in this survey are in accordance with those found in other publications. There are reports of magnesium sulfate induction doses in general anesthesia from $15 \mathrm{mg} \cdot \mathrm{kg}^{-1}$ to $75 \mathrm{mg} \cdot \mathrm{kg}^{-1}$ (Beşogul et al., 2009; Gozdemir et al., 2010; Rotava et al., 2013; Kahraman and Eroglu, 2014; Rodrigo et al., 2014; Honarmand et al., 2015; Rower et al., 2017) and doses up to $50 \mathrm{mg} \cdot \mathrm{kg}^{-1}$ in sedation (Lecuyer et al., 2017).

We observed that the Brazilian anesthesiologist uses magnesium sulfate rationally. Clinical effects, doses and routes of administration are found in the literature.

This survey describes the wide range of purposes magnesium sulfate is used for in anesthesia in Brazil. Although anesthesiologists have free access to the use of magnesium sulfate, research data have shown that the drug has been used primarily in those indications approved by the Health Authorities and/or supported by critical evaluation of systematic reviews and meta-analyzes. The frequency of its use is related to the amount and strength of evidence of its effects reported in the literature.

This survey has some limitations. Only Brazilian anesthesiologists participated in the study. Further, the participation of the anesthesiologists was voluntary; those

\section{REFERENCES}

Abdulatif, M., Ahmed, A., Mukhtar, A., and Badawy, S. (2013). The effect of magnesium sulphate infusion on the incidence and severity of emergence agitation in children undergoing adenotonsillectomy using sevoflurane anaesthesia. Anaesthesia 68, 1045-1052. doi: 10.1111/anae.12380

Agrawal, A., Agrawal, S., and Payal, Y. S. (2014). Effect of continuous magnesium sulfate infusion on spinal block characteristics: a prospective study. Saudi J. Anaesth. 8, 78-82. doi: 10.4103/1658-354X.125945 who agreed to participate are likely those most interested in the use of magnesium sulfate in anesthesia. This may have created bias that could interfere with the generalization of the responses to the full population of anesthesia specialists. Only $10 \%$ effectively responded to the survey, that the results may thus be biased. The questionnaire was not validated.

We conclude that magnesium sulfate is among the five most commonly used adjuvants in anesthesia, along with clonidine, ketamine, lidocaine and dexmedetomidine. Several clinical effects for magnesium sulfate were reported, especially postoperative analgesia, reduction of anesthetic consumption and the prevention and treatment of preeclampsia and eclampsia seizures. Hypotension, residual neuromuscular blockade, hypermagnesemia and pain on intravenous injection were the most frequent adverse events and, in general, were considered mild. Magnesium sulfate intravenous doses used in most general anesthesia induction were between 30 and $40 \mathrm{mg} \cdot \mathrm{kg}^{-1}$.

\section{ETHICS STATEMENT}

This study was carried out in accordance with the recommendations of Brazilian National Health Council (Resolution number 466, from December 12, 2012) with written informed consent from all subjects. All subjects gave written informed consent in accordance with the Declaration of Helsinki. The protocol was approved by the Research Ethics Committee of the Fluminense Federal University, Niterói, RJ, Brazil (CAAE 35038614.0.0000.5243, opinion 884.839, dated 11/13/2014).

\section{AUTHOR CONTRIBUTIONS}

IC, FL, and MS designed the study and performed the experiments, IC, RCF, EB, and NV analyzed the data and wrote the manuscript.

\section{FUNDING}

The study was supported by the Fluminense Federal University, Niterói, Brazil and Brazilian Society of Anesthesiology, Rio de Janeiro, Brazil. There was no funding source for this study.

\section{SUPPLEMENTARY MATERIAL}

The Supplementary Material for this article can be found online at: https://www.frontiersin.org/articles/10.3389/fphar. 2019.00429/full\#supplementary-material

Ahsan, B., Rahimi, E., Moradi, A., and Rashadmanesh, N. (2014). The effects of magnesium sulphate on succinylcholine-induced fasciculation during induction of general anaesthesia. J. Pak. Med. Assoc. 64, 1151-1153.

Altura, B. M. (1994). Introduction: importance of Mg in physiology and medicine and the need for ion selective electrodes. Scand. J. Clin. Lab. Invest. Suppl. 217, 5-9. doi: 10.1080/00365519409095206

Altura, B. M., and Altura, B. T. (1996). Role of magnesium in patho-physiological processes and the clinical utility of magnesium ion selective electrodes. Scand. J. Clin. Lab. Invest. Suppl. 224, 211-234. doi: 10.3109/00365519609088642 
Bakan, M., Topuz, U., Umutoglu, T., Gundogdu, G., Ilce, Z., Elicevik, M., et al. (2014). Remifentanil-based total intravenous anesthesia for pediatric rigid bronchoscopy: comparison of adjuvant propofol and ketamine. Clinics 69, 372-377. doi: 10.6061/clinics/2014(06)01

Berhan, Y., and Berhan, A. (2015). Should magnesium sulfate be administered to women with mild pre-eclampsia? A systematic review of published reports on eclampsia. J. Obstet. Gynaecol. Res. 41, 831-842. doi: 10.1111/jog.12697

Beşogul, Y., Gemalmaz, H., and Aslan, R. (2009). Effects of preoperative magnesium therapy on arrhythmias and myocardial ischemia during off-pump coronary surgery. Ann. Thorac. Med. 4, 137-139. doi: 10.4103/1817-1737.53355

Brookfield, K. F., Elkomy, M., Su, F., Drover, D. R., and Carvalho, B. (2017). Optimization of maternal magnesium sulfate administration for fetal neuroprotection: application of a prospectively constructed pharmacokinetic model to the BEAM cohort. J. Clin. Pharmacol. 57, 1419-1424. doi: 10.1002/jcph.941

Crowther, C. A., Brown, J., McKinlay, C. J., and Middleton, P. (2014). Magnesium sulphate for preventing preterm birth in threatened preterm labour. Cochr. Datab. Syst. Rev. 15:CD001060. doi: 10.1002/14651858.CD001060.pub2

Czarnetzki, C., Lysakowski, C., Elia, N., and Tramèr, M. R. (2010). Time course of rocuronium-induced neuromuscular block after pre-treatment with magnesium sulphate: a randomised study. Acta Anaesthesiol. Scand. 54, 299-306. doi: 10.1111/j.1399-6576.2009.02160.x

Dabbagh, A., Elyasi, H., Razavi, S. S., Fathi, M., and Rajaei, S. (2009). Intravenous magnesium sulfate for post-operative pain in patients undergoing lower limb orthopedic surgery. Acta Anaesthesiol. Scand. 53, 1088-1091. doi: $10.1111 / \mathrm{j} .1399-6576.2009 .02025 . \mathrm{x}$

Del Castillo, J., and Engbaek, L. (1954). The nature of the neuromuscular block produced by magnesium. J. Physiol. 124, 370-384. doi: 10.1113/jphysiol.1954.sp005114

Demiroglu, M., Ün, C., Ornek, D. H., Kici, O., Yildirim, A. E., Horasanli, E., et al. (2016). The effect of systemic and regional use of magnesium sulfate on postoperative tramadol consumption in lumbar disc surgery. Biomed Res. Int. 2016:3216246. doi: 10.1155/2016/3216246

Dubé, L., and Granry, J. C. (2003). The therapeutic use of magnesium in anesthesiology, intensive care and emergency medicine: a review. Can. J. Anaesth. 50, 732-746. doi: 10.1007/BF03018719

Forget, P., and Cata, J. (2017). Stable anesthesia with alternative to opioids: Are ketamine and magnesium helpful in stabilizing hemodynamics during surgery? A systematic review and meta-analyses of randomized controlled trials. Res Clin Anaesthesiol. 31, 523-531. doi: 10.1016/j.bpa.2017.07.001

Fuchs-Buder, T., Wilder-Smith, O. H., Borgeat, A., and Tassonyi, E. (1995). Interaction of magnesium sulphate with vecuronium-induced neuromuscular block. Br. J. Anaesth. 74, 405-409. doi: 10.1093/bja/74.4.405

Germano Filho, P. A., Cavalcanti, I. L., Barrucand, L., and Verçosa, N. (2015). Effect of magnesium sulphate on sugammadex reversal time for neuromuscular blockade: a randomised controlled study. Anaesthesia 70, 956-961. doi: 10.1111/anae.12987

Giovannitti, J. A., Thoms, S. M., and Crawford, J. J. (2015). Alpha-2 adrenergic receptor agonists: a review of current clinical applications. Anesth. Prog. 62, 31-38. doi: 10.2344/0003-3006-62.1.31

Gozdemir, M., Usta, B., Demircioglu, R. I., Muslu, B., Sert, H., and Karatas, O. F. (2010). Magnesium sulfate infusion prevents shivering during transurethral prostatectomy with spinal anesthesia: a randomized, double-blinded, controlled study. J. Clin. Anesth. 22, 184-189. doi: 10.1016/j.jclinane.2009.06.006

Green, R. H. (2016). Asthma in adults (acute): magnesium sulfate treatment. Clin. Evid. 01:1513

Griffiths, B., and Kew, K. M. (2016). Intravenous magnesium sulfate for treating children with acute asthma in the emergency department. Cochr. Datab. Syst. Rev. 4:Cd011050. doi: 10.1002/14651858.CD011050.pub2

Gupta, K., Vohra, V., and Sood, J. (2006). The role of magnesium as an adjuvant during general anaesthesia. Anaesthesia 61, 1058-1063. doi: 10.1111/j.1365-2044.2006.04801.x

Haryalchi, K., Abedinzade, M., Khanaki, K., Mansour Ghanaie, M., and Mohammad Zadeh, F. (2017). Whether preventive low dose magnesium sulphate infusion has an influence on postoperative pain perception and the level of serum beta-endorphin throughout the total abdominal hysterectomy. Rev. Esp. Anestesiol. Reanim. 64, 384-390. doi: 10.1016/j.redar.2016.11.009
Herroeder, S., Schönherr, M. E., De Hert, S. G., and Hollmann, M. W. (2011) Magnesium-essentials for anesthesiologists. Anesthesiology 114, 971-993. doi: 10.1097/ALN.0b013e318210483d

Honarmand, A., Safavi, M., Badiei, S., and Daftari-Fard, N. (2015). Different doses of intravenous magnesium sulfate on cardiovascular changes following the laryngoscopy and tracheal intubation: a double-blind randomized controlled trial. J. Res. Pharm. Pract. 4, 79-84. doi: 10.4103/2279-042X.1 54365

Hwang, J. Y., Na, H. S., Jeon, Y. T., Ro, Y. J., Kim, C. S., and Do, S. H. (2010). I.V. infusion of magnesium sulphate during spinal anaesthesia improves postoperative analgesia. Br. J. Anaesth. 104, 89-93. doi: 10.1093/bja/a ep334

James, M. F., and Cronjé, L. (2004). Pheochromocytoma crisis: the use of magnesium sulfate. Anesth. Analg. 99, 680-686. doi: 10.1213/01.ANE.0000133136.01381.52

Jangra, K., Malhotra, S. K., Gupta, A., and Arora, S. (2016). Comparison of quality of the surgical field after controlled hypotension using esmolol and magnesium sulfate during endoscopic sinus surgery. J. Anaesthesiol. Clin. Pharmacol. 32, 325-328. doi: 10.4103/0970-9185.173400

Jee, D., Lee, D., Yun, S., and Lee, C. (2009). Magnesium sulphate attenuates arterial pressure increase during laparoscopic cholecystectomy. Br. J. Anaesth. 103, 484-489. doi: 10.1093/bja/aep196

Juibari, H. M., Eftekharian, H. R., and Arabion, H. R. (2016). Intravenous magnesium sulfate to deliberate hypotension and bleeding after bimaxillary orthognathic surgery; a randomized double-blind controlled trial. J. Dent. $17,276-282$.

Kahraman, F., and Eroglu, A. (2014). The effect of intravenous magnesium sulfate infusion on sensory spinal block and postoperative pain score in abdominal hysterectomy. Biomed Res. Int. 2014:236024. doi: 10.1155/2014/2 36024

Kew, K. M., Kirtchuk, L., and Michell, C. I. (2014). Intravenous magnesium sulfate for treating adults with acute asthma in the emergency department. Cochr. Datab. Syst. Rev. 28:CD010909. doi: 10.1002/14651858.CD0 10909

Kim, J. E., Shin, C. S., Lee, Y. C., Lee, H. S., Ban, M., and Kim, S. Y. (2015). Beneficial effect of intravenous magnesium during endoscopic submucosal dissection for gastric neoplasm. Surg. Endosc. 29, 3795-3802. doi: 10.1007/s00464-015-4514-1

Koinig, H., Wallner, T., Marhofer, P., Andel, H., Hörauf, K., and Mayer, N. (1998). Magnesium sulfate reduces intra- and postoperative analgesic requirements. Anesth. Analg. 87, 206-210.

Kranke, P., Jokinen, J., Pace, N. L., Schnabel, A., Hollmann, M. W., Hahnenkamp, K., et al. (2015). Continuous intravenous perioperative lidocaine infusion for postoperative pain and recovery. Cochr. Datab. Syst. Rev. 16:CD009642. doi: 10.1002/14651858.CD009642.pub2

Kussman, B., Shorten, G., Uppington, J., and Comunale, M. E. (1997). Administration of magnesium sulphate before rocuronium: effects on speed of onset and duration of neuromuscular block. Br. J. Anaesth. 79, 122-124. doi: 10.1093/bja/79.1.122

Kutlesic, M. S., Kutlesic, R. M., and Mostic-Ilic, T. (2017). Magnesium in obstetric anesthesia and intensive care. J. Anesth. 31, 127-139. doi: 10.1007/s00540-016-2257-3

Lecuyer, M., Rubio, M., Chollat, C., Lecointre, M., Jégou, S., Leroux, P., et al. (2017). Experimental and clinical evidence of differential effects of magnesium sulfate on neuroprotection and angiogenesis in the fetal brain. Pharmacol. Res. Perspect. 5, e00315. doi: 10.1002/prp2.315

Locks, G. D. F., Cavalcanti, I. L., Duarte, N. M., Da Cunha, R. M., and De Almeida, M. C. (2015). Use of neuromuscular blockers in Brazil. Braz. J. Anesthesiol. 65, 319-325. doi: 10.1016/j.bjan.2015.03.001

Maged, A. M., Hashem, A. M., Gad Allah, S. H., Mahy, M. E., Mostafa, W. A., and Kotb, A. (2016). The effect of loading dose of magnesium sulfate on uterine, umbilical, and fetal middle cerebral arteries Doppler in women with severe preeclampsia: a case control study. Hypertens. Pregnancy 35, 91-99. doi: 10.3109/10641955.2015.1116552

Marret, S., and Ancel, P. (2016). Neuroprotection for preterm infants with antenatal magnesium sulphate. J. Gynecol. Obstet. Biol. Reprod. 45, 1418-1433. doi: 10.1016/j.jgyn.2016.09.028

Marzban, S., Haddadi, S., Naghipour, M. R., Sayah Varg, Z., and Naderi Nabi, B. (2014). The effect of intravenous magnesium sulfate on laryngospasm after 
elective adenotonsillectomy surgery in children. Anesth. Pain Med. 4:e15960. doi: 10.5812/aapm.15960

McKeown, A., Seppi, V., and Hodgson, R. (2017). Intravenous magnesium sulphate for analgesia after caesarean section: a systematic review. Anesthesiol. Res. Pract. 2017:9186374. doi: 10.1155/2017/9186374.

Mendonca, F. T., de Queiroz, L. M., Guimaraes, C. C., and Xavier, A. C. (2017). Effects of lidocaine and magnesium sulfate in attenuating hemodynamic response to tracheal intubation: single-center, prospective, double-blind, randomized study. Rev. Bras. Anestesiol. 67, 50-56. doi: 10.1016/j.bjane.2015.08.004

Mentes, O., Harlak, A., Yigit, T., Balkan, A., Balkan, M., Cosar, A., et al. (2008). Effect of intraoperative magnesium sulphate infusion on pain relief after laparoscopic cholecystectomy. Acta Anaesthesiol. Scand. 52, 1353-1359. doi: 10.1111/j.1399-6576.2008.01816.x

Naghipour, B., Faridaalaee, G., Shadvar, K., Bilehjani, E., Khabaz, A. H., and Fakhari, S. (2016). Effect of prophylaxis of magnesium sulfate for reduction of postcardiac surgery arrhythmia: randomized clinical trial. Ann. Card. Anaesth. 19, 662-667. doi: 10.4103/0971-9784.191577

Naguib, M., Kopman, A. F., Lien, C. A., Hunter, J. M., Lopez, A., and Brull, S. J. (2010). A survey of current management of neuromuscular block in the United States and Europe. Anesth. Analg. 111, 110-119. doi: 10.1213/ANE.0b013e3181c07428

Puri, G. D., Marudhachalam, K. S., Chari, P., and Suri, R. K. (1998). The effect of magnesium sulphate on hemodynamics and its efficacy in attenuating the response to endotracheal intubation in patients with coronary artery disease. Anesth. Analg. 87, 808-811.

Rhee, E., Beiswenger, T., Oguejiofor, C. E., and James, A. H. (2012). The effects of magnesium sulfate on maternal and fetal platelet aggregation. J. Matern. Fetal Neonatal Med. 25, 478-483. doi: 10.3109/14767058.2011.584087

Rodrigo, C., Fernando, D., and Rajapakse, S. (2014). Pharmacological management of tetanus: an evidence-based review. Crit Care 18:217. doi: 10.1186/cc13797

Rodríguez-Rubio, L., Del Pozo, J. S. G., Nava, E., and Jordan, J. (2016). Interaction between magnesium sulfate and neuromuscular blockers during the perioperative period. A systematic review and meta-analysis. J. Clin. Anesth. 34, 524-534. doi: 10.1016/j.jclinane.2016.06.011

Rodríguez-Rubio, L., Nava, E., Del Pozo, J. S. G., and Jordán, J. (2017). Influence of the perioperative administration of magnesium sulfate on the total dose of anesthetics during general anesthesia. A systematic review and meta-analysis. J. Clin. Anesth. 39, 129-138. doi: 10.1016/j.jclinane.2017.03.038

Roscoe, A., and Ahmed, A. B. (2003). A survey of peri-operative use of magnesium sulphate in adult cardiac surgery in the UK. Anaesthesia 58, 363-365. doi: 10.1046/j.1365-2044.2003.03082_1.x

Rotava, P., Cavalcanti, I. L., Barrucand, L., Vane, L. A., and Verçosa, N. (2013). Effects of magnesium sulphate on the pharmacodynamics of rocuronium in patients aged 60 years and older: a randomised trial. Eur. J. Anaesthesiol. 30, 599-604. doi: 10.1097/EJA.0b013e328361d342

Rower, J. E., Liu, X., Yu, T., Mundorff, M., Sherwin, C. M., and Johnson, M. D. (2017). Clinical pharmacokinetics of magnesium sulfate in the treatment of children with severe acute asthma. Eur. J. Clin. Pharmacol. 73, 325-331. doi: 10.1007/s00228-016-2165-3

Ryu, J. H., Kang, M. H., Park, K. S., and Do, S. H. (2008). Effects of magnesium sulphate on intraoperative anaesthetic requirements and postoperative analgesia in gynaecology patients receiving total intravenous anaesthesia. $\mathrm{Br}$. J. Anaesth. 100, 397-403. doi: 10.1093/bja/aem407

Safavi, M., Honarmand, A., Sahaf, A. S., Sahaf, S. M., Attari, M., Payandeh, M., et al. (2015). Magnesium sulfate versus lidocaine pretreatment for prevention of pain on etomidate injection: a randomized, double-blinded placebo controlled trial. J. Res. Pharm. Pract. 4, 4-8. doi: 10.4103/2279-042X.150044

Salaminia, S., Sayehmiri, F., Angha, P., Sayehmiri, K., and Motedayen, M. (2018). Evaluating the effect of magnesium supplementation and cardiac arrhythmias after acute coronary syndrome: a systematic review and meta-analysis. $B M C$ Cardiovasc. Disord. 18:129. doi: 10.1186/s12872-018-0857-6

Schmid-Elsaesser, R., Kunz, M., Zausinger, S., Prueckner, S., Briegel, J., and Steiger, H. J. (2006). Intravenous magnesium versus nimodipine in the treatment of patients with aneurysmal subarachnoid hemorrhage: a randomized study. Neurosurgery 58, 1054-1065. doi: 10.1227/01.NEU.0000215868.40441.D9

Seyhan, T. O., Tugrul, M., Sungur, M. O., Kayacan, S., Telci, L., Pembeci, K., et al. (2006). Effects of three different dose regimens of magnesium on propofol requirements, haemodynamic variables and postoperative pain relief in gynaecological surgery. Br. J. Anaesth. 96, 247-252. doi: 10.1093/bja/aei291

Shin, Y. H., Choi, S. J., Jeong, H. Y., and Kim, M. H. (2011). Evaluation of dose effects of magnesium sulfate on rocuronium injection pain and hemodynamic changes by laryngoscopy and endotracheal intubation. Korean J. Anesthesiol. 60, 329-333. doi: 10.4097/kjae.2011.60.5.329

Soltani, H. A., Hashemi, S. J., Montazeri, K., Dehghani, A., and Nematbakhsh, M. (2016). The role of magnesium sulfate in tracheal intubation without muscle relaxation in patients undergoing ophthalmic surgery. J. Res. Med. Sci. 21:96. doi: 10.4103/1735-1995.193168

Srebro, D. P., Vucković, S., Vujović, K. S., and Prostran, M. (2014). Antihyperalgesic effect of systemic magnesium sulfate in carrageenan-induced inflammatory pain in rats: influence of the nitric oxide pathway. Magnes. Res. 27, 77-85. doi: 10.1684/mrh.2014.0364

Thomas, S. H., and Behr, E. R. (2016). Pharmacological treatment of acquired QT prolongation and torsades de pointes. Br. J. Clin. Pharmacol. 81, 420-427. doi: $10.1111 /$ bcp. 12726

Toraman, F., Karabulut, E. H., Alhan, H. C., Dagdelen, S., and Tarcan, S. (2001). Magnesium infusion dramatically decreases the incidence of atrial fibrillation after coronary artery bypass grafting. Ann. Thorac. Surg. 72, 1256-1261. doi: 10.1016/S0003-4975(01)02898-3

Ulm, M. A., Watson, C. H., Vaddadi, P., Wan, J. Y., and Santoso, J. T. (2016). Hypomagnesemia is prevalent in patients undergoing gynecologic surgery by a gynecologic oncologist. Int. J. Gynecol. Cancer 26, 1320-1326. doi: 10.1097/IGC.0000000000000766

Uludag, E. Ü., Gözükara, I. Ö., Kucur, S. K., Ulug, P., Özdegirmenci, Ö., and Erkaya, S. (2014). Maternal magnesium level effect on preterm labor treatment. J. Matern. Fetal Neonatal Med. 27, 1449-1453. doi: $10.3109 / 14767058.2013 .858688$

Vendrell, M., Martín, N., Tejedor, A., Ortiz, J. T., Muxí, À., and Taurà, P. (2016). Magnesium sulphate and (123)I-MIBG in pheochromocytoma: two useful techniques for a complicated disease. Rev. Esp. Anestesiol. Reanim. 63, 48-53. doi: 10.1016/j.redar.2015.04.001

Vigil-De Gracia, P., and Ludmir, J. (2015). The use of magnesium sulfate for women with severe preeclampsia or eclampsia diagnosed during the postpartum period. Matern Fetal Neonatal Med. 28, 2207-2209. doi: $10.3109 / 14767058.2014 .982529$

Wilson, M. S., Ingersoll, M., Meschter, E., Bodea-Braescu, A. V., and Edwards, R. K. (2014). Evaluating the side effects of treatment for preterm labor in a center that uses "high-dose" magnesium sulfate. Am. J. Perinatol. 31, 711-716. doi: 10.1055/s-0033-1358770

Wong, G. K., Chan, M. T., Boet, R., Poon, W. S., and Gin, T. (2006). Intravenous magnesium sulfate after aneurysmal subarachnoid hemorrhage: a prospective randomized pilot study. J. Neurosurg. Anesthesiol. 18, 142-148. doi: 10.1097/00008506-200604000-00009

Xie, M., Li, X. K., and Chen, J. (2016). Effect of magnesium sulphate infusion on emergence agitation in patients undergoing esophageal carcinoma with general anesthesia: a randomized, double-blind, controlled trial. Nan Fang Yi Ke Da Xиe Xue Bao 36, 1650-1654.

Xie, M., Li, X. K., and Peng, Y. (2017). Magnesium sulfate for postoperative complications in children undergoing tonsillectomies: a systematic review and meta-analysis. J. Evid. Based Med. 10, 16-25. doi: 10.1111/jebm.12230

Zhang, J., Wang, Y., Xu, H., and Yang, J. (2018). Influence of magnesium sulfate on hemodynamic responses during laparoscopic cholecystectomy. A meta-analysis of randomized controlled studies. Medicine 97:e12747. doi: 10.1097/MD.0000000000012747

Conflict of Interest Statement: The authors declare that the research was conducted in the absence of any commercial or financial relationships that could be construed as a potential conflict of interest.

Copyright $\odot 2019$ Cavalcanti, Lima, Silva, Cruz Filho, Braga and Verçosa. This is an open-access article distributed under the terms of the Creative Commons Attribution License (CC BY). The use, distribution or reproduction in other forums is permitted, provided the original author $(s)$ and the copyright owner(s) are credited and that the original publication in this journal is cited, in accordance with accepted academic practice. No use, distribution or reproduction is permitted which does not comply with these terms. 